\title{
Characterization of eleven monosomic alien addition lines added from Gossypium anomalum to Gossypium hirsutum using improved GISH and SSR markers
}

Xiaoxiao Wang ${ }^{1}$, Yingying Wang ${ }^{1}$, Chen Wang ${ }^{1}$, Yu Chen ${ }^{1}$, Yu Chen ${ }^{1,2}$, Shouli Feng ${ }^{1}$, Ting Zhao ${ }^{1}$ and Baoliang Zhou ${ }^{1 *}$ (D)

\begin{abstract}
Background: Gossypium anomalum (BB genome) possesses the desirable characteristics of drought tolerance, resistance to diseases and insect pests, and the potential for high quality fibers. However, it is difficult to transfer the genes associated with these desirable traits into cultivated cotton (G. hirsutum, AADD genome). Monosomic alien addition lines (MAALs) can be used as a bridge to transfer desired genes from wild species into G. hirsutum. In cotton, however, the high number and smaller size of the chromosomes has resulted in difficulties in discriminating chromosomes from wild species in cultivated cotton background, the development of cotton MAALs has lagged far behind many other crops. To date, no set of G. hirsutum-G. anomalum MAALs was reported. Here the amphiploid (AADDBB genome) derived from $G$. hirsutum $\times G$. anomalum was used to generate a set of $G$. hirsutum-G. anomalum MAALs through a combination of consecutive backcrossing, genomic in situ hybridization (GISH), morphological survey and microsatellite marker identification.
\end{abstract}

Results: We improved the GISH technique used in our previous research by using a mixture of two probes from G. anomalum and G. herbaceum (AA genome). The results indicate that a ratio of 4:3 (G. anomalum : G. herbaceum) is the most suitable for discrimination of chromosomes from $\mathrm{G}$. anomalum and the At-subgenome of $G$. hirsutum. Using this improved GISH technique, 108 MAAL individuals were isolated. Next, 170 G. hirsutum- and G. anomalum-specific codominant markers were obtained and employed for characterization of these MAAL individuals. Finally, eleven out of 13 MAALs were identified. Unfortunately, we were unable to isolate Chrs. $1 \mathrm{~B}^{\mathrm{a}}$ and $5 \mathrm{~B}^{\mathrm{a}}$ due to their very low incidences in backcrossing generation, as these remained in a condition of multiple additions.

Conclusions: The characterized lines can be employed as bridges for the transfer of desired genes from G. anomalum into G. hirsutum, as well as for gene assignment, isolation of chromosome-specific probes, development of chromosome-specific "paints" for fluorochrome-labeled DNA fragments, physical mapping, and selective isolation and mapping of cDNAs/genes for a particular G. anomalum chromosome.

Keywords: Gossypium hirsutum, Gossypium anomalum, Chromosome, Monosomic alien addition line, Genomic in situ hybridization, Microsatellite marker

\footnotetext{
* Correspondence: baoliangzhou@njau.edu.cn

${ }^{1}$ State Key Laboratory of Crop Genetics \& Germplasm Enhancement, Nanjing

Agricultural University, Nanjing 210095, China

Full list of author information is available at the end of the article
} 


\section{Background}

Cotton is the leading natural textile fiber crop in the world. Approximately $5 \%$ of the world's arable land is used for cotton planting, generating about $\$ 630.6$ billion in 2011 [1]. Cotton belongs to the Gossypium genus of Malvaceae, which contains five tetraploid species $(2 n=$ $4 \times=52$, AADD genome) and approximately 45 diploid species (eight genomes from A to $G$ and $K, 2 n=2 \times=26$ ) [2]. Upland cotton (G. hirsutum) is the most widely cultivated species and its production accounts for over 95\% of the world's cotton production [3]. During the development of its cultivars, cotton has been subjected to long-term artificial selection, which narrowed its genetic base and gave rise to several difficulties in breeding. Cotton breeders face a scarcity of genetically diverse resources, therefore expanding the genetic base of cotton cultivars is imperative. Wild or untapped species have many excellent characteristics and contain abundant desirable genes, which have yet to be unlocked by prebreeding. G. anomalum $(2 \mathrm{n}=2 \times=26, \mathrm{BB}$ genome $)$ which is native to Africa, mainly Angola and Namibia [2], has the favorable characteristics of drought tolerance and resistance to diseases (cotton wilt, angular leaf spot) and insect pests (springtails, aphids): more importantly, it also possesses genes with the potential to produce high quality fibers (good fiber strength and
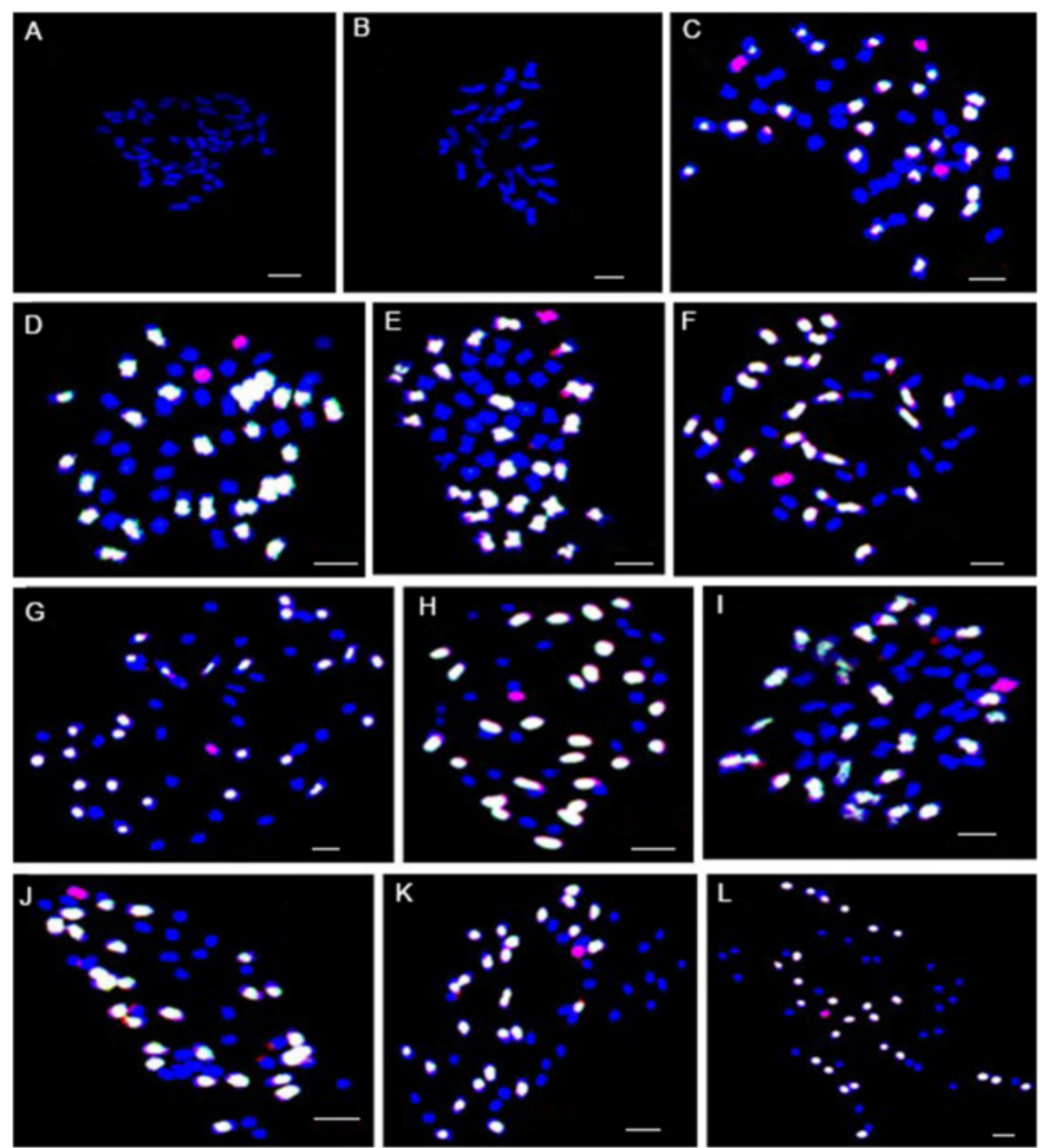

Fig. 1 Genomic in situ hybridization of the putative alien chromosomes of G. anomalum in the G. hirsutum background using two G. herbaceum and G. anomalum probes. Genomic DNA from G. anomalum and G. herbaceum was labeled with digoxigenin-11-dUTP and Bio-16-dUTP by nick translation, respectively. Chromosomes of the At-subgenome of $G$. hirsutum were cross-hybridized with both the $G$. anomalum and $G$. herbaceum probes and produced white signals and chromosomes of the Dt-subgenome of G. hirsutum were stained with 4',6-diamidino-2-phenylindole (DAPI) and produced blue signals. Chromosomes from G. anomalum were hybridized with $G$. anomalum probe and produced red signals. a mitotic chromosome spread of the 52 chromosomes of $G$. hirsutum. $\mathbf{b}$ mitotic chromosome spread of the 26 chromosomes of $G$. anomalum. c-I mitotic chromosome spread showing the 52 G. hirsutum (white and blue) chromosomes and three (c), two (d), and one (e, $\mathbf{f}, \mathbf{g}, \mathbf{h}, \mathbf{i}, \mathbf{j}, \mathbf{k}$ and $\mathbf{I})$ individual chromosomes of $G$. anomalum (red), respectively. Scale bar $=5 \mu \mathrm{m}$ 
fineness) [4] and cytoplasmic male sterility [5-7]. However, it is difficult to transfer these desirable genes into cultivated cotton through conventional breeding methods due to the isolation of wild species from cultivated species, which limits chromosome pairing and genetic recombination.

Monosomic alien addition lines (MAALs) contain only one alien chromosome in addition to the receptor background chromosomes. MAALs can be used as a bridge to transfer desired genes from wild species into G. hirsutum [8]. Over the past two decades, MAALs have been widely available for numerous crops [9], and these can be used for effectively identifying favorable genes in wild species, allowing for more accurate and faster transfer of such genes to create introgression lines, the effect of specific alien chromosomes to be examined, homeologies with chromosomes of cultivated species to be compared $[10,11]$, and physical maps of specific chromosomes to be constructed [12]. In cotton, however, the high number and smaller size of the chromosomes has resulted in difficulties in discriminating chromosomes from wild species in cultivated cotton background, therefore the development of cotton MAALs has lagged far behind many other crops. No set of cotton MAALs was reported until cotton molecular genetic maps were constructed and a genomic in situ hybridization (GISH) technique for cotton was developed. Previously, only one complete set of G. hirsutum-G. australe MAALs had been developed using simple sequence repeat (SSR) markers and GISH $[9,13,14]$. Two G. hirsutum-G. somalense MAALs and several G. hirsutum-G. sturtianum MAALs have also been obtained $[11,15]$.

In this study, the G. hirsutum-G. anomalum hexaploid was used as a maternal parent in the continuous backcrossing with upland cotton (recipient parent, G. hirsutum acc. TM-1), and eleven MAALs were isolated using GISH and SSR markers. These MAALs may be useful for mining and transferring favorable genes from G. anomalum into G. hirsutum on a genome-wide scale, mapping genes on chromosomes, analyzing genome structure and evolution, and micro-cloning for chromosomespecific library construction.

\section{Results}

Alien chromosomes from G. anomalum in G. hirsutum were examined by the improved GISH

The GISH technique used in our previous research was improved as follows. Genomic DNA extracted from G. anomalum and G. herbaceum was labeled with digoxigenin-11-dUTP and Bio-16-dUTP (Roche Diagnostics, Mannheim, Germany) by nick translation, respectively. The labeled DNA was mixed at a variety of ratios for GISH analysis using chromosomes from the mitotic metaphases as target templates. The results indicate that a ratio of 4:3 is the most suitable for discrimination of chromosomes from G. anomalum and the Atsubgenome of G. hirsutum. At this ratio the chromosomes from G. anomalum only hybridized with the G. anomalum probe to produce a red signal, while chromosomes of the At-subgenome of G. hirsutum cross-hybridized with both the G. anomalum and G. herbaceum probes to produce a white signal and chromosomes of the Dt-subgenome of $G$. hirsutum were stained with 4;6-diamidino-2-phenylindole (DAPI) (Roche Diagnostics), producing a blue color. Therefore, the GISH technique has been improved and can be further used to differentiate chromosomes from G. anomalum and the At-subgenome of G. hirsutum (Fig. 1).

Table 1 Incidence of alien chromosomes in the $B C_{1}$ to $B C_{2} G$. hirsutum $\times G$. anomalum generations

\begin{tabular}{lllllllllllllll}
\hline Chromosome number & $1 \mathrm{~B}^{\mathrm{a}}$ & $2 \mathrm{~B}^{\mathrm{a}}$ & $3 \mathrm{~B}^{\mathrm{a}}$ & $4 \mathrm{~B}^{\mathrm{a}}$ & $5 \mathrm{~B}^{\mathrm{a}}$ & $6 \mathrm{~B}^{\mathrm{a}}$ & $7 \mathrm{~B}^{\mathrm{a}}$ & $8 \mathrm{~B}^{\mathrm{a}}$ & $9 \mathrm{~B}^{\mathrm{a}}$ & $10 \mathrm{~B}^{\mathrm{a}}$ & $11 \mathrm{~B}^{\mathrm{a}}$ & $12 \mathrm{~B}^{\mathrm{a}}$ & $13 \mathrm{~B}^{\mathrm{a}}$ & $\mathrm{No}_{\text {individuals }}$ \\
\hline 52 & 0 & 0 & 0 & 0 & 0 & 0 & 0 & 0 & 0 & 0 & 0 & 0 & 0 & 122 \\
$52+1$ & 0 & 10 & 1 & 17 & 0 & 16 & 3 & 6 & 1 & 34 & 2 & 7 & 11 & 108 \\
$52+2$ & 1 & 9 & 6 & 31 & 1 & 16 & 5 & 1 & 0 & 19 & 5 & 13 & 1 & 54 \\
$52+3$ & 3 & 2 & 6 & 9 & 1 & 8 & 5 & 1 & 0 & 5 & 4 & 7 & 4 & 19 \\
$52+4$ & 1 & 2 & 4 & 2 & 1 & 4 & 1 & 1 & 2 & 2 & 0 & 4 & 1 & 6 \\
$52+5$ & 2 & 1 & 3 & 2 & 3 & 1 & 1 & 2 & 1 & 1 & 1 & 1 & 1 & 4 \\
$52+6$ & 4 & 3 & 4 & 1 & 2 & 1 & 3 & 3 & 2 & 3 & 3 & 2 & 4 & 7 \\
$52+7$ & 1 & 1 & 2 & 0 & 2 & 1 & 1 & 0 & 1 & 0 & 1 & 2 & 2 & 2 \\
$52+8$ & 2 & 1 & 2 & 2 & 0 & 1 & 1 & 1 & 1 & 2 & 1 & 1 & 1 & 2 \\
$52+9$ & 2 & 2 & 2 & 1 & 0 & 2 & 2 & 2 & 1 & 2 & 1 & 1 & 0 & 2 \\
$52+13$ & 2 & 2 & 2 & 2 & 2 & 2 & 2 & 2 & 2 & 2 & 2 & 2 & 2 & 2 \\
SUM & 16 & 31 & 30 & 65 & 10 & 50 & 22 & 17 & 9 & 68 & 18 & 38 & 25 & 328 \\
Incidence (\%) & 4.65 & 7.33 & 7.58 & 15.89 & 2.69 & 12.47 & 5.62 & 4.16 & 2.44 & 16.87 & 4.65 & 9.29 & 6.36 \\
Monosomic addition (\%) & 0.00 & 9.26 & 0.93 & 15.74 & 0.00 & 14.81 & 2.78 & 5.56 & 0.93 & 31.48 & 1.85 & 6.48 & 10.19
\end{tabular}


Table 2 SSR primers used for screening G. anomalum chromosomes in the alien addition lines

\begin{tabular}{|c|c|c|c|c|c|c|c|c|c|c|c|c|c|}
\hline Chromosome & $1 \mathrm{~B}^{\mathrm{a}}$ & $2 \mathrm{~B}^{\mathrm{a}}$ & $3 \mathrm{~B}^{\mathrm{a}}$ & $4 \mathrm{~B}^{\mathrm{a}}$ & $5 \mathrm{~B}^{\mathrm{a}}$ & $6 \mathrm{~B}^{\mathrm{a}}$ & $7 \mathrm{~B}^{\mathrm{a}}$ & $8 \mathrm{~B}^{\mathrm{a}}$ & $9 \mathrm{~B}^{\mathrm{a}}$ & $10 B^{a}$ & $11 \mathrm{~B}^{\mathrm{a}}$ & $12 \mathrm{~B}^{\mathrm{a}}$ & $13 \mathrm{~B}^{\mathrm{a}}$ \\
\hline & NAU7675-120 & NAU1847-200 & NAU2836-230 & NAU6966-200 & NAU3095-260 & NAU3677-160 & NAU8250-220 & NAU0104-230 & NAU3100-170 & NAU7772-160 & NAU8254-160 & NAU3084-250 & NAU6582-550 \\
\hline & NAU3347-250 & NAU3733-200 & NAU0093-130 & NAU0210-200 & NAU2503-250 & NAU2679-150 & NAU7974-150 & NAU8183-160 & NAU1886-150 & NAU2543-190 & NAU7698-160 & NAU0206-100 & NAU6426-370 \\
\hline & NAU7914-160 & NAU0645-130 & NAU5675-180 & NAU0012-230 & NAU3183-230 & NAU1454-200 & NAU2556-250 & NAU0738-230 & NAU3888-220 & NAU3917-180 & NAU3731-300 & NAU5397-160 & NAU3011-220 \\
\hline & NAU3714-190 & NAU8013-220 & NAU0354-180 & NAU0569-160 & NAU0144-250 & NAU1987-160 & NAU2974-150 & NAU2876-200 & NAU6701-200 & NAU4071-220 & NAU0133-120 & NAU7007-150 & NAU7727-250 \\
\hline & NAU0072-180 & NAU5490-280 & NAU0200-410 & NAU3508-200 & NAU6205-160 & NAU2397-270 & NAU0300-120 & NAU5130-320 & NAU0148-170 & NAU7900-150 & NAU0646-140 & NAU3905-150 & NAU3948-250 \\
\hline & NAU3337-320 & NAU5421-210 & NAU3875-210 & NAU0146-180 & NAU4055-170 & NAU6347-170 & NAU4017-220 & NAU7616-150 & NAU6848-150 & NAU3531-210 & NAU7140-150 & NAU2715-200 & NAU0039-110 \\
\hline & NAU6624-220 & NAU1778-100 & NAU0088-140 & NAU0033-150 & NAU0378-180 & NAU0783-180 & NAU0121-200 & NAU0583-300 & NAU2753-250 & NAU3665-220 & NAU5418-160 & NAU7838-150 & NAU8306-130 \\
\hline & NAU0107-110 & NAU6474-300 & NAU3700-180 & NAU7579-140 & NAU6406-200 & NAU0356-170 & NAU3594-110 & NAU5335-150 & NAU0075-130 & NAU0922-200 & NAU6999-420 & NAU8230-170 & NAU2443-140 \\
\hline & NAU7670-150 & NAU7809-200 & NAU2908-200 & NAU7290-230 & NAU5486-200 & NAU4682-150 & NAU4956-280 & NAU6389-270 & NAU7815-250 & NAU3137-300 & NAU5212-200 & NAU7719-200 & NAU7738-160 \\
\hline & NAU1495-170 & NAU3598-200 & NAU8203-230 & NAU7946-150 & NAU2944-180 & NAU2714-170 & NAU2820-200 & NAU0435-180 & NAU6984-200 & NAU4881-240 & NAU2361-250 & NAU7824-190 & NAU6738-130 \\
\hline & NAU6095-170 & NAU3820-110 & NAU3292-270 & NAU6993-150 & NAU0123-120 & & NAU7686-180 & NAU0069-160 & NAU7743-130 & NAU8079-200 & NAU3373-220 & NAU1274-210 & NAU4871-150 \\
\hline & & NAU1702-180 & NAU5111-230 & & NAU6830-150 & & NAU2597-180 & NAU3904-190 & NAU0799-210 & NAU0142-500 & NAU2602-270 & NAU8006-160 & NAU3447-110 \\
\hline & & & NAU0805-190 & & NAU7747-160 & & NAU7692-150 & NAU0298-130 & NAU8120-320 & NAU7983-170 & NAU6809-160 & & \\
\hline & & & & & NAU2655-170 & & & & NAU0245-110 & & NAU6315-180 & & \\
\hline & & & & & NAU7015-150 & & & & NAU0864-240 & & NAU6267-180 & & \\
\hline & & & & & NAU3826-420 & & & & NAU4477-250 & & NAU6520-200 & & \\
\hline & & & & & NAU3609-250 & & & & & & & & \\
\hline & & & & & NAU3656-210 & & & & & & & & \\
\hline Total & 11 & 12 & 13 & 11 & 18 & 10 & 13 & 13 & 16 & 13 & 16 & 12 & 12 \\
\hline Position & $8.20-120.01$ & $0.00-107.44$ & $3.23-126.25$ & $0.00-113.51$ & 10.90-189.98 & $13.32-121.59$ & $2.85-121.07$ & $0.00-149.89$ & $0.00-148.34$ & $15.49-111.16$ & $12.11-156.15$ & $0.00-108.09$ & $7.24-106.43$ \\
\hline $\mathrm{GDC}(\mathrm{cM} /)^{\mathrm{a}}$ & 111.81 & 107.44 & 123.02 & 113.51 & 179.08 & 108.27 & 118.22 & 149.89 & 148.34 & 95.67 & 144.04 & 108.09 & 99.19 \\
\hline Mean density ${ }^{b}$ & 10.16 & 8.95 & 9.46 & 10.32 & 9.95 & 10.83 & 9.09 & 11.53 & 9.27 & 7.36 & 9.00 & 9.01 & 8.27 \\
\hline PCC (\%) $)^{c}$ & 88.93 & 95.88 & 97.44 & 88.94 & 94.27 & 78.54 & 91.35 & 90.33 & 98.14 & 82.84 & 79.51 & 80.86 & 84.64 \\
\hline
\end{tabular}

Note: ${ }^{\mathrm{a}} \mathrm{GDC}$ genetic distance coverage (cM); ${ }^{\mathrm{b}} \mathrm{Genetic}$ distance (cM) between two adjacent markers on a chromosome; ${ }^{\mathrm{c} P e r c e n t a g e}$ of chromosome covered by markers (\%) 
Progenies of the pentaploid of (G. hirsutum $\times$ G. anomalum) $\times$ G. hirsutum backcrossed with $G$. hirsutum were subjected to GISH to determine the number of alien chromosomes transferred from G. anomalum to G. hirsutum using visible fluorescent hybridization signals. Thirty eight individuals of the $\mathrm{BC}_{1}$ population were examined by GISH analysis (Additional file 1: Table S1). The analysis demonstrated that $27(71.05 \%)$ carried 2 to 6 alien chromosomes, and 6 (15.79\%) carried 7 to 9 alien chromosomes. Only two (5.26 \%) individuals carried one chromosome, $6 \mathrm{~B}^{\mathrm{a}}$ and $13 \mathrm{~B}^{\mathrm{a}}$ of G. anomalum, resepctively. One (2.63\%) plant had no alien chromosomes and the final two (5.26\%) plants had 13 alien chromosomes from G. anomalum (Fig. 1; Table 1).

A total of 290 individuals from the $\mathrm{BC}_{2}$ generation were further analyzed by GISH. The results indicated that $106(36.55 \%)$ individuals had one alien chromosome of G. anomalum and 121 (41.72 \%) had no alien chromosomes in the G. hirsutum background. 50
$(17.24 \%)$ and $10(3.45 \%)$ individuals carried two and three alien chromosomes, respectively, and another 1 $(0.34 \%)$ carried four alien chromosomes. The results demonstrated that most of the $\mathrm{BC}_{2}$ individuals carried 0-1 alien chromosomes, and only a small number contained multiple alien chromosomes (Fig. 1; Table 1).

\section{Screening of a set of putative G. anomalum chromosome- specific SSR primer pairs}

During the evolution of Gossypium, chromosomal translocations occurred between genomes $A_{1}, A_{2}$, and $B_{1}$, while genome $\mathrm{D}$ remained relatively stable [16]. $\mathrm{Nu}$ merous recent reports also show that translocations occurred between chromosomes in the At-subgenome of the tetraploids [17], while no large structural variation was found in the Dt-subgenome. Therefore, we only selected SSR primers from the Dt -subgenome of the tetraploid cotton linkage map to screen putative G. anomalum chromosome-specific SSR primer pairs. Of

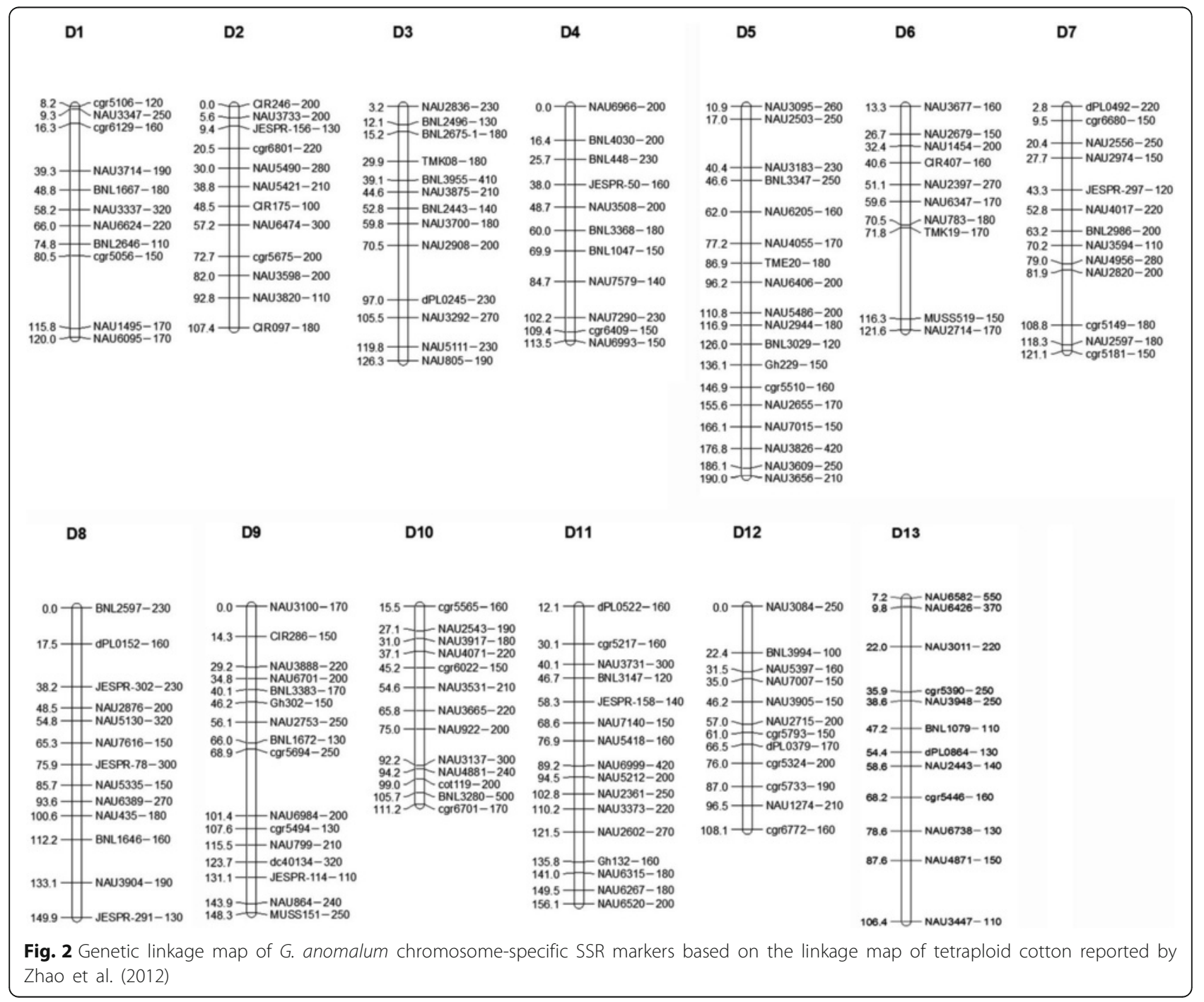


the 1402 pairs of primers we selected, 1072 amplified distinct fragments in G. hirsutum and G. anomalum, including 272 dominant markers of G. hirsutum, 194 dominant markers of G. anomalum and 452 codominant markers, while 154 pairs produced no amplified polymorphic bands and another 330 pairs produced vague bands, which were excluded from further study. Then, based on the tetraploid cotton linkage map constructed by our institute [17], the above 452 codominant markers were located, and of these, 170 wellamplified and evenly distributed codominant markers within an interval of $10 \mathrm{cM}$ were finally selected for use in genotyping the entire $\mathrm{BC}_{1} \mathrm{~F}_{1}$ and $\mathrm{BC}_{2} \mathrm{~F}_{1}$ population. The 170 codominant markers were distributed on the Dt-subgenome chromosomes, ranging from 10 to 18 markers per chromosome, with coverage of 80.9-100.0 $\%$ and a density of $6.7-15.0 \mathrm{cM}$ of each chromosome (Table 2; Fig. 2). The G. anomalum-specific SSR markers could be used to track and identify the alien chromosomes from G. anomalum in G. hirsutum.

\section{Identity of alien chromosomes from G. anomalum as discriminated by SSR analysis}

One hundred seventy G. hirsutum- and G. anomalumspecific codominant markers distributed on $13 \mathrm{Dt}$ subgenome chromosomes of the tetraploids were used to identify the alien chromosomes in 108 MAALs and multiple alien addition lines. The results demonstrated that $34(31.48 \%)$ MAAL individuals were MAAL-10B ${ }^{\mathrm{a}}$ (the largest group), followed by 17 (15.74 \%) MAAL-4B ${ }^{\mathrm{a}}$, 16 (14.81 \%) MAAL-6B ${ }^{\mathrm{a}}, 11$ (10.19 \%) MAAL-13B ${ }^{\mathrm{a}}, 10$ (9.26 \%) MAAL-2B ${ }^{\mathrm{a}}, 7$ (6.48 \%) MAAL-12B ${ }^{\mathrm{a}}, 3$ (2.78 \%) MAAL-7B ${ }^{\mathrm{a}}, 2$ (1.85 \%) MAAL-11B ${ }^{\mathrm{a}}, 1$ (0.93 \%) MAAL$3 \mathrm{~B}^{\mathrm{a}}$, and 1 (0.93 \%) MAAL-9B ${ }^{\mathrm{a}}$ (Figs. 3 and 4; Table 1). Two MAALs were not found, MAAL- $1 B^{a}$ and MAAL$5 \mathrm{~B}^{\mathrm{a}}$; therefore Chrs. $1 \mathrm{~B}^{\mathrm{a}}$ and $5 \mathrm{~B}^{\mathrm{a}}$ were not isolated and remained as multiple addition lines.

During the development of MAALs, Chr. $10 \mathrm{~B}^{\mathrm{a}}$ appeared most frequently, with an incidence of $16.87 \%$, followed by $15.89 \%$ for $4 \mathrm{~B}^{\mathrm{a}}, 12.47 \%$ for $6 \mathrm{~B}^{\mathrm{a}}$, and $9.29 \%$ for $12 \mathrm{~B}^{\mathrm{a}}$. Chrs. $5 \mathrm{~B}^{\mathrm{a}}$ and $9 \mathrm{~B}^{\mathrm{a}}$ showed very low incidences of $2.69 \%$ and $2.44 \%$ (Table 1 ).

\section{Morphological traits of MAALs}

Morphological data were gathered during the cotton growing stage. The results shown in Tables 3, 4 and 5 indicate that the eleven MAALs differed from one another and also differed from their parents in terms of their morphological traits, such as plant type, leaf shape, size of flower and boll (Figs. 5 and 6; Tables 3, 4 and 5). Most of these MAALs grew slower than the recipient, TM-1. We found that MAAL- $8 \mathrm{~B}^{\mathrm{a}}$ leaves had a very dark green
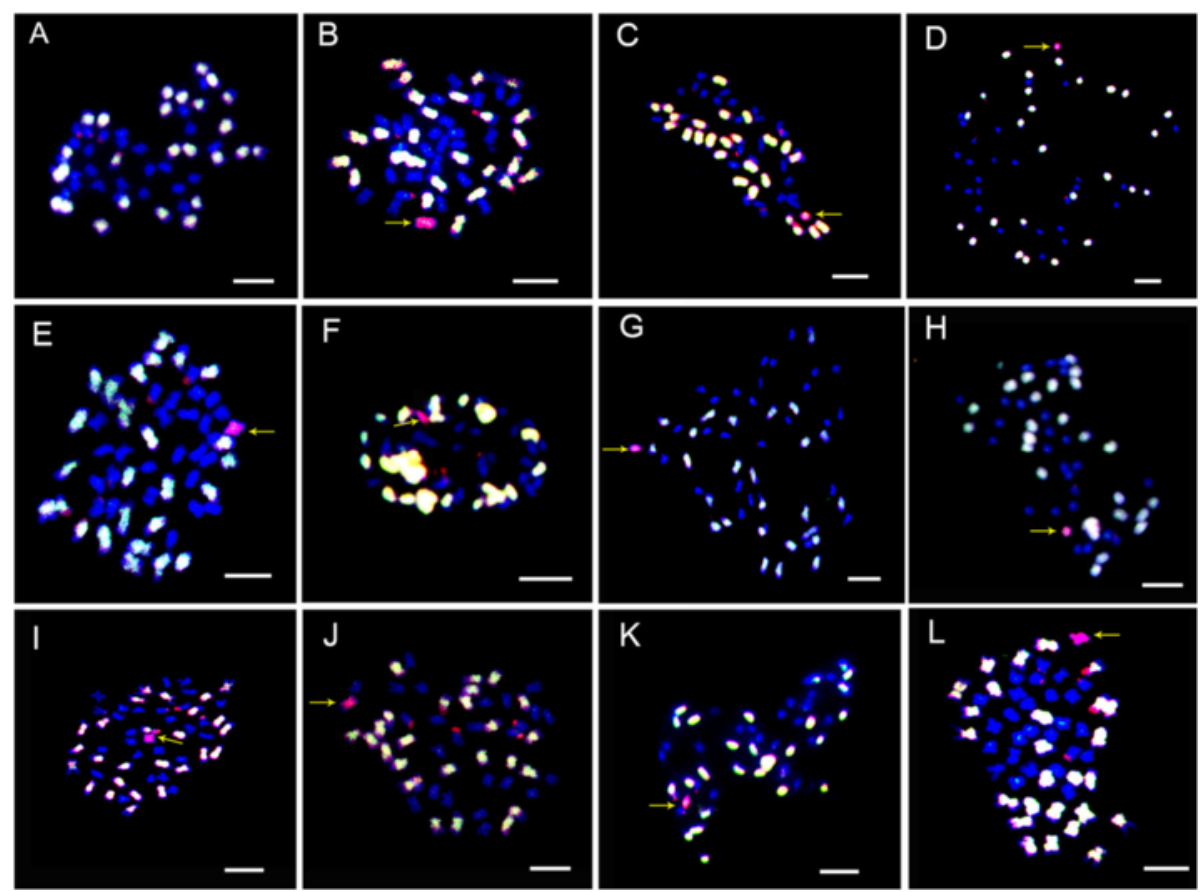

Fig. 3 Genomic in situ hybridization of the putative monosomic alien chromosomes of G. anomalum in the G. hirsutum background using $G$. herbaceum and G. anomalum probes. a mitotic chromosome spread of the 52 chromosomes of G. hirsutum, showing 26 chromosomes each of the At- (white) and Dt- (blue) subgenomes. b-I mitotic chromosome spread showing the $52 \mathrm{G}$. hirsutum (white and blue) chromosomes and different individual chromosomes from $G$. anomalum (red), corresponding to $2 B^{a}$ to $4 G^{a}$ (b, $\mathbf{c}$ and $\mathbf{d}$ ) and $6 G^{a}$ to $13 G^{a}(\mathbf{e}, \mathbf{f}, \mathbf{g}, \mathbf{h}, \mathbf{i}, \mathbf{j}, \mathbf{k}$ and $\mathbf{I})$, respectively. Scale bar $=5 \mu \mathrm{m}$ 




Fig. 4 A set of $G$. anomalum-specific SSR markers were used to identify individual alien chromosomes of G. anomalum in G. hirsutum. a-k the G. anomalum-specific amplicons were obtained using 11 individual chromosome-specific primer pairs for markers; NAU5421, BNL2443, NAU7579, NAU3677, dPL0492, BNL2597, BNL3383, NAU4881, NAU9520, dPL0379, and dPL0864. The chromosomes correspond to $D_{2}$ to $D_{4}$ and $D_{6}$ to $D_{13}$ in cultivated tetraploid cotton. P1, G. hirsutum; $\mathbf{P 2}$, G. anomalum; F1, the hexaploid of G. hirsutum and G. anomalum; 1-11 show that each of these plants possesses a single different individual chromosome from $G$. anomalum, corresponding to $2 \mathrm{~B}^{\mathrm{a}}$ to $4 \mathrm{~B}^{\mathrm{a}}$, and $6 \mathrm{~B}^{\mathrm{a}}$ to $13 \mathrm{~B}^{\mathrm{a}}$. $\mathbf{M}$, molecular size marker (50 bp ladder). Arrows (red) indicate chromosome-specific markers for G. anomalum

color. We also observed that MAAL-7B ${ }^{\mathrm{a}}$, MAAL-12B and MAAL-13B ${ }^{\mathrm{a}}$ had relatively bigger leaves, while MAAL- $8 B^{\mathrm{a}}$, MAAL- $9 \mathrm{~B}^{\mathrm{a}}$ and MAAL- $10 \mathrm{~B}^{\mathrm{a}}$ had relatively smaller leaves than the other lines (Fig. $5 \mathrm{~b}$ ). In addition, MAAL- $6 B^{a}$, MAAL- $10 B^{a}$, MAAL- $11 B^{a}$ and MAAL- $12 B^{a}$ had relatively larger flowers than the others. Only MAAL- $7 \mathrm{~B}^{\mathrm{a}}$ showed petal spots and MAAL- $6 \mathrm{~B}^{\mathrm{a}}$ had very light brown fibers, indicating that genes for petal spots and light brown fibers are located on chromosomes $7 \mathrm{~B}^{\mathrm{a}}$ and $6 \mathrm{~B}^{\mathrm{a}}$ (Figs. 5a and $6 \mathrm{~d}$ ), respectively. MAAL-2 $\mathrm{B}^{\mathrm{a}}$ and MAAL- $12 \mathrm{~B}^{\mathrm{a}}$ had relatively longer bolls and MAAL- $7 \mathrm{~B}^{\mathrm{a}}$ had the widest boll diameter, while MAAL- $8 \mathrm{~B}^{\mathrm{a}}$ had the shortest bolls and MAAL-10B ${ }^{a}$ had the smallest boll diameter (Fig. 6c). MAAL-6B ${ }^{\mathrm{a}}$, MAAL-7B ${ }^{\mathrm{a}}$ and MAAL$9 \mathrm{~B}^{\mathrm{a}}$ had a relatively larger boll weight, while MAAL- $8 \mathrm{~B}^{\mathrm{a}}$, MAAL- $10 B^{a}$ and MAAL- $11 B^{a}$ had a relatively smaller boll weight than the others (Table 4). We found that MAAL-7 $\mathrm{B}^{\mathrm{a}}$ had longer fibers than the others (Fig.6d)

\section{Discussion}

MAALs are powerful tools in crop breeding since they can be used to produce alien translocation and substitution lines, to study interspecific relationships, and to construct single chromosome libraries. They can also be used in gene mining, gene assignment, gene expression pattern analysis, gene function analysis, physical gene mapping, isolation of chromosome-specific probes, selective isolation and mapping of cDNA/gene of a particular chromosome. Numerous reports have shown that the development of MAALs has been successfully achieved in many crops such as wheat [18-21], rice [22] tomato [23], potato [24], cucumber [25], tobacco [26], oat [12], sugar beet [27, 28], and rapeseed [29, 30]. MAALs have played and are playing important roles in numerous types of plant genomic research. The development of MAALs in Gossypium began as early as the 1980s but greatly lagged behind other crops due to the large number $(2 n=52)$ and small size of chromosomes, which led to difficulty in accurately discriminating each chromosome, therefore, little progress has been made in cotton. So far only one set of MAALs has been completed [9], and this work benefited from advances in the development of GISH and molecular markers in cotton.

However, in this study, due to the very close relationship between chromosomes of the At-subgenome in G. hirsutum and those in G. anomalum often leading to cross-hybridization in GISH, we had to first improve the GISH technique by adjusting the ratio of the two different probes used. We tried five different combinations and found that the ratio of $4: 3$ was more suitable than any others for the discrimination of chromosomes from G. anomalum and the At-subgenome of G. hirsutum. Therefore, using a combination of the improved GISH methodology, G. anomalum chromosome-specific SSR molecular markers and conventional morphological survey, eleven MAALs were isolated and characterized, and two remain to be isolated from multiple addition states by further backcrossing.

Several previous reports showed that G. anomalum contains the favorable characteristics of drought tolerance and resistance to diseases (cotton Verticillium wilt, angular leaf spot) and insect pests (springtails, aphids); and more importantly, it also possesses genes with the 
Table 3 Morphological characteristics of the eleven MAALs

\begin{tabular}{|c|c|c|c|c|c|c|c|c|c|c|c|c|c|c|}
\hline Characters & $\mathrm{TM}-1$ & G. anomalum & Hexaploid $F_{1}$ & $2 \mathrm{~B}^{\mathrm{a}}$ & $3 \mathrm{~B}^{\mathrm{a}}$ & $4 \mathrm{~B}^{\mathrm{a}}$ & $6 \mathrm{~B}^{\mathrm{a}}$ & $7 \mathrm{~B}^{\mathrm{a}}$ & $8 \mathrm{~B}^{\mathrm{a}}$ & $9 B^{a}$ & $10 \mathrm{~B}^{\mathrm{a}}$ & $11 \mathrm{~B}^{\mathrm{a}}$ & $12 \mathrm{~B}^{\mathrm{a}}$ & $13 \mathrm{~B}^{\mathrm{a}}$ \\
\hline Petal color & Creamy & Mauve & Creamy & Creamy & Creamy & Creamy & Creamy & Creamy & Creamy & Creamy & Creamy & Creamy & Creamy & Creamy \\
\hline Petal spot & Absent & Big dark red & Big dark red & Absent & Absent & Absent & Absent & light red & Absent & Absent & Absent & Absent & Absent & Absent \\
\hline $\begin{array}{l}\text { Petal length } \\
(\mathrm{cm})\end{array}$ & $4.04 \pm 0.13$ & $3.77 \pm 0.49$ & $4.75 \pm 0.13$ & $4.14 \pm 0.32$ & $4.19 \pm 0.29$ & $4.1 \pm 0.32$ & $4.37 \pm 0.38$ & $3.92 \pm 0.31$ & $3.57 \pm 0.52$ & $3.78 \pm 0.51$ & $4.49 \pm 0.44$ & $4.84 \pm 0.41$ & $4.53 \pm 0.48$ & $3.68 \pm 0.21$ \\
\hline $\begin{array}{l}\text { Petal width } \\
(\mathrm{cm})\end{array}$ & $4.43 \pm 0.20$ & $4.37 \pm 0.57$ & $5.28 \pm 0.28$ & $4.32 \pm 0.37$ & $4.13 \pm 0.22$ & $4.01 \pm 0.39$ & $4.67 \pm 0.52$ & $4.24 \pm 0.45$ & $3.59 \pm 0.66$ & $3.76 \pm 0.21$ & $4.42 \pm 0.44$ & $5.39 \pm 0.68$ & $4.77 \pm 0.58$ & $3.53 \pm 0.54$ \\
\hline $\begin{array}{l}\text { Another } \\
\text { number }\end{array}$ & $104 \pm 4.97$ & $69.33 \pm 8.50$ & $112.25 \pm 10.69$ & $96.36 \pm 5.00$ & $85.33 \pm 8.08$ & $92.50 \pm 9.98$ & $96.19 \pm 12.58$ & $68.44 \pm 12.28$ & $67.22 \pm 9.39$ & $97.40 \pm 10.88$ & $108.27 \pm 9.21$ & $109.83 \pm 12.30$ & $105.91 \pm 12.24$ & $92.09 \pm 8.51$ \\
\hline $\begin{array}{l}\text { Style length } \\
(\mathrm{cm})\end{array}$ & $2.26 \pm 0.05$ & $1.70 \pm 0.10$ & $2.55 \pm 0.17$ & $2.19 \pm 0.21$ & $2.02 \pm 0.06$ & $1.76 \pm 0.18$ & $2.74 \pm 0.24$ & $1.78 \pm 0.25$ & $2.27 \pm 0.20$ & $2.25 \pm 0.40$ & $2.46 \pm 0.32$ & $2.60 \pm 0.29$ & $1.84 \pm 0.17$ & $2.10 \pm 0.19$ \\
\hline $\begin{array}{l}\text { Stigma length } \\
(\mathrm{cm})\end{array}$ & $1.06 \pm 0.09$ & $0.43 \pm 0.15$ & $1.18 \pm 0.15$ & $1.09 \pm 0.18$ & $1.23 \pm 0.20$ & $0.81 \pm 0.15$ & $1.52 \pm 0.26$ & $0.83 \pm 0.11$ & $1.28 \pm 0.20$ & $1.05 \pm 0.11$ & $0.95 \pm 0.38$ & $1.51 \pm 0.28$ & $0.85 \pm 0.12$ & $1.11 \pm 0.07$ \\
\hline $\begin{array}{l}\text { Pedicel length } \\
(\mathrm{cm})\end{array}$ & $1.05 \pm 0.21$ & $0.90 \pm 0.10$ & $1.88 \pm 0.25$ & $1.42 \pm 0.40$ & $1.22 \pm 0.38$ & $0.83 \pm 0.15$ & $2.52 \pm 0.82$ & $1.25 \pm 0.34$ & $0.78 \pm 0.13$ & $1.21 \pm 0.26$ & $1.01 \pm 0.30$ & $0.87 \pm 0.27$ & $2.97 \pm 1.40$ & $0.73 \pm 0.12$ \\
\hline $\begin{array}{l}\text { sepal length } \\
(\mathrm{cm})\end{array}$ & $3.06 \pm 0.05$ & $1.95 \pm 0.13$ & $3.05 \pm 0.17$ & $3.17 \pm 0.23$ & $3.33 \pm 0.26$ & $2.99 \pm 0.35$ & $3.40 \pm 0.29$ & $2.98 \pm 0.29$ & $2.86 \pm 0.10$ & $2.88 \pm 0.20$ & $2.90 \pm 0.29$ & $3.19 \pm 0.37$ & $3.09 \pm 0.38$ & $2.90 \pm 0.25$ \\
\hline $\begin{array}{l}\text { sepal width } \\
(\mathrm{cm})\end{array}$ & $1.10 \pm 0.14$ & $0.93 \pm 0.10$ & $1.00 \pm 0.20$ & $1.19 \pm 0.39$ & $1.27 \pm 0.12$ & $0.96 \pm 0.14$ & $1.12 \pm 0.14$ & $1.34 \pm 0.29$ & $0.83 \pm 0.11$ & $0.85 \pm 0.12$ & $0.87 \pm 0.14$ & $1.10 \pm 0.14$ & $1.19 \pm 0.24$ & $1.05 \pm 0.22$ \\
\hline $\begin{array}{l}\text { Bracteole length } \\
(\mathrm{cm})\end{array}$ & $4.72 \pm 0.50$ & $1.52 \pm 0.08$ & $4.72 \pm 0.32$ & $5.28 \pm 0.45$ & $4.97 \pm 0.28$ & $4.19 \pm 0.72$ & $4.83 \pm 0.63$ & $4.84 \pm 0.66$ & $3.76 \pm 0.37$ & $4.41 \pm 0.38$ & $4.35 \pm 0.58$ & $5.20 \pm 0.47$ & $5.18 \pm 0.61$ & $3.47 \pm 0.34$ \\
\hline $\begin{array}{l}\text { Bracteole width } \\
(\mathrm{cm})\end{array}$ & $2.85 \pm 0.24$ & $0.47 \pm 0.07$ & $2.98 \pm 0.31$ & $3.15 \pm 0.35$ & $2.57 \pm 0.23$ & $2.75 \pm 0.48$ & $3.23 \pm 0.46$ & $2.74 \pm 0.45$ & $2.47 \pm 0.36$ & $2.84 \pm 0.37$ & $2.56 \pm 0.44$ & $3.30 \pm 0.27$ & $3.16 \pm 0.42$ & $2.53 \pm 0.24$ \\
\hline Leaf color & Green & light Green & Green & Green & Green & Green & Green & Green & Dark green & Green & Green & Green & Green & Green \\
\hline leaf length (cm) & $12.03 \pm 1.17$ & $4.40 \pm 0.36$ & $6.57 \pm 0.38$ & $10.58 \pm 2.28$ & $9.75 \pm 2.47$ & $9.34 \pm 2.25$ & $9.10 \pm 1.96$ & $10.19 \pm 1.03$ & $7.66 \pm 1.65$ & $7.75 \pm 0.21$ & $7.70 \pm 0.98$ & $9.33 \pm 3.75$ & $10.17 \pm 1.90$ & $9.36 \pm 1.74$ \\
\hline leaf width $(\mathrm{cm})$ & $11.70 \pm 0.20$ & $2.53 \pm 0.21$ & $8.40 \pm 0.56$ & $11.68 \pm 2.67$ & $10.80 \pm 2.69$ & $11.46 \pm 1.57$ & $10.72 \pm 2.20^{*}$ & $12.53 \pm 1.72$ & $10.52 \pm 2.87$ & $8.73 \pm 0.11$ & $8.40 \pm 1.29$ & $10.90 \pm 3.72$ & $11.27 \pm 1.20$ & $12.08 \pm 2.10$ \\
\hline $\begin{array}{l}\text { Petiole length } \\
(\mathrm{cm})\end{array}$ & $6.7 \pm 1.49$ & $7.67 \pm 0.47$ & $8.57 \pm 0.90$ & $6.51 \pm 2.00$ & $4.60 \pm 1.27$ & $6.83 \pm 0.85$ & $5.71 \pm 1.73$ & $6.55 \pm 1.14$ & $6.65 \pm 2.56$ & $8.75 \pm 0.503$ & $5.60 \pm 1.27$ & $7.03 \pm 3.48$ & $7.52 \pm 0.92$ & $9.51 \pm 1.69$ \\
\hline $\begin{array}{l}\text { boll length } \\
(\mathrm{mm})\end{array}$ & $43.08 \pm 2.06$ & $20.08 \pm 1.01$ & $33.18 \pm 1.35$ & $43.90 \pm 2.94$ & $38.75 \pm 1.03$ & $34.52 \pm 1.62$ & $34.03 \pm 1.94$ & $36.16 \pm 1.41$ & $30.58 \pm 2.84$ & $41.78 \pm 0.10$ & $34.02 \pm 1.96$ & $38.60 \pm 12.00$ & $48.88 \pm 1.94$ & $35.05 \pm 2.037$ \\
\hline boll width (mm) & $39.31 \pm 1.38$ & $10.44 \pm 0.61$ & $22.34 \pm 1.72$ & $31.70 \pm 3.22$ & $41.75 \pm 1.02$ & $39.05 \pm 2.19$ & $39.82 \pm 2.10$ & $42.25 \pm 2.16$ & $31.25 \pm 2.10$ & $31.86 \pm 1.82$ & $25.52 \pm 1.89$ & $31.70 \pm 2.26$ & $33.38 \pm 2.24$ & $40.74 \pm 2.54$ \\
\hline $\begin{array}{l}\text { boll tip length } \\
(\mathrm{mm})\end{array}$ & $3.89 \pm 0.68$ & $3.46 \pm 0.59$ & $5.06 \pm 1.57$ & $4.44 \pm 0.95$ & $4.07 \pm 0.55$ & $3.72 \pm 0.85$ & $4.94 \pm 1.93$ & $3.18 \pm 0.84$ & $3.15 \pm 1.59$ & $2.98 \pm 1.71$ & $4.08 \pm 1.17$ & $4.17 \pm 1.27$ & $5.48 \pm 1.68$ & $2.04 \pm 1.10$ \\
\hline
\end{tabular}


Table 4 The yield-related traits of the eleven MAALs

\begin{tabular}{llll}
\hline MAAL & Boll size $(\mathrm{g})$ & Seed index $(\mathrm{g} / 100)$ & Lint percentage (\%) \\
\hline $2 \mathrm{~B}^{\mathrm{a}}$ & 3.15 & 13.05 & 30.27 \\
$3 \mathrm{~B}^{\mathrm{a}}$ & 3.89 & 14.17 & 34.45 \\
$4 \mathrm{~B}^{\mathrm{a}}$ & 4.19 & 12.87 & 36.86 \\
$6 \mathrm{~B}^{\mathrm{a}}$ & 5.02 & 14.94 & 32.24 \\
$7 \mathrm{~B}^{\mathrm{a}}$ & 5.01 & 13.74 & 35.95 \\
$8 \mathrm{~B}^{\mathrm{a}}$ & 2.98 & 10.29 & 36.70 \\
$9 \mathrm{~B}^{\mathrm{a}}$ & 5.49 & 13.13 & 34.14 \\
$10 \mathrm{~B}^{\mathrm{a}}$ & 2.30 & 9.35 & 29.46 \\
$11 \mathrm{~B}^{\mathrm{a}}$ & 2.41 & 9.38 & 30.35 \\
$12 \mathrm{~B}^{\mathrm{a}}$ & 4.25 & 14.92 & 28.13 \\
$13 \mathrm{~B}^{\mathrm{a}}$ & 4.44 & 14.91 & 35.30 \\
$\mathrm{TM}^{\mathrm{a}}-1(\mathrm{CK})$ & 5.64 & 14.91 & 28.16 \\
\hline
\end{tabular}

potential to produce high quality fibers (good fiber strength and fineness) [4] and cytoplasmic male sterility [5-7]. Our previous reports also demonstrated that using G. anomalum as a donor parent and G. hirsutum as a recipient parent, a series of introgression lines with longer, stronger and finer fibers has been developed [31]. Shen et al. [32] mapped QTLs on Chr. 7 affecting fiber length in an $\mathrm{F}_{2}$ population derived from $\mathrm{G}$. anomalum introgression line 7235 crossed with TM-1. However, in this study, we investigated some agronomic traits of MAALs and observed that most MAALs had poor performances in fiber quality or fiber yield components, implying that the added alien chromosomes had negative effects on most agronomic traits (Tables 4 and 6; Fig. 6). For example, the bolls of all MAALs were lighter than those of the recipient TM-1; and the fibers of all six MAALs were shorter than TM-1 (the fiber properties of the other five MAALs were not measured due to a lack of fiber samples). The resultant phenomena may be

Table 5 Summary of the unique traits of the monosomic alien addition lines

\begin{tabular}{ll}
\hline MAAL & Unique traits \\
\hline $2 \mathrm{~B}^{\mathrm{a}}$ & Long leaves and long calyx teeth of bract \\
$3 \mathrm{~B}^{\mathrm{a}}$ & Short petiole and long Sepal \\
$4 \mathrm{~B}^{\mathrm{a}}$ & Short column and stigma, high lint percent \\
$6 \mathrm{~B}^{\mathrm{a}}$ & Long column and stigma, light brown fiber \\
$7 \mathrm{~B}^{\mathrm{a}}$ & Purple petal spot, large leaves, long fiber \\
$8 \mathrm{~B}^{\mathrm{a}}$ & Small bracts and flowers with few anthers, dark green leaves \\
$9 \mathrm{~B}^{\mathrm{a}}$ & High boll weight \\
$10 \mathrm{~B}^{\mathrm{a}}$ & Small leaves and bolls, many fruit branch and bolls \\
$11 \mathrm{~B}^{\mathrm{a}}$ & Large flowers and the maximum anthers \\
$12 \mathrm{~B}^{\mathrm{a}}$ & Long tips of cone-shape bolls and long pedicels \\
$13 \mathrm{~B}^{\mathrm{a}}$ & Short peduncle and fruit branch, round and big bolls \\
\hline
\end{tabular}

caused by linkage drag, which means that there were very close linkages between favorable and unfavorable genes on the same chromosome, even though the fibers of some MAALs were found to be stronger than those of TM-1. Therefore, to enhance the transfer of desirable genes and eliminate undesirable genes from G. anomalum, it is necessary to break the linkage drags to promote chromosome recombination between G. hirsutum and G. anomalum. The development of chromosome translocation lines or introgression lines may be an alternative choice based on the MAALs. We deeply believe that these MAALs of G. hirsutum-G. anomalum would be a powerful tool for systematically transferring desirable genes chromosome by chromosome from G. anomalum into G. hirsutum, as well as for gene mining, gene assignment, gene function analysis, gene physical mapping, isolation of chromosome-specific probes, selective isolation and mapping of cDNAs for a particular chromosome, and genomic research.

\section{Conclusions}

From this study, we draw two conclusions. (1) The GISH technique used in our previous research has been improved by using a mixture of two probes at a ratio of 4:3 (G. anomalum and G. herbaceum) to avoid cross-hybridization caused by the very close relationship between chromosomes from G. anomalum and the At-subgenome of $G$. hirsutum, which can be suitable for recognizing alien chromosomes of G. anomalum in G. hirsutum background. (2) Eleven out of 13 potential MAALs were isolated, which would be used, at the chromosome level, for effectively identifying favorable genes in G. anomalum, allowing for more accurate and faster transfer of such genes to create introgression lines, the effect of specific alien chromosomes to be examined, homeologies with chromosomes of cultivated species to be compared, and physical maps of specific chromosomes to be constructed.

\section{Methods}

\section{Plant materials}

In 2012, the amphiploid (allohexaploid) ( $2 \mathrm{n}=6 \mathrm{x}=78$, AADDBB genome) (previously obtained in our institue) derived from the doubled triploid hybrid of G. hirsutum $(2 \mathrm{n}=4 \times=52$, AADD genome $) \times G$. anomalum $(2 \mathrm{n}=2 \times$ $=26$, BB genome, obtained from Cotton Research Institute of Chinese Academy of Agricultural Sciences) was backcrossed as a maternal parent with $G$. hirsutum acc TM-1, the genetic standard line of upland cotton. In 2013, two pentaploid individuals were obtained at Pailou Experimental Station of Nanjing Agricultural University (PES/NJAU) and used as both paternal and maternal parents in the backcross with TM-1. The $\mathrm{BC}_{1}$ seeds obtained were planted in plastic cups with sterilized soil and incubated in the phytotron at Nanjing Agricultural 


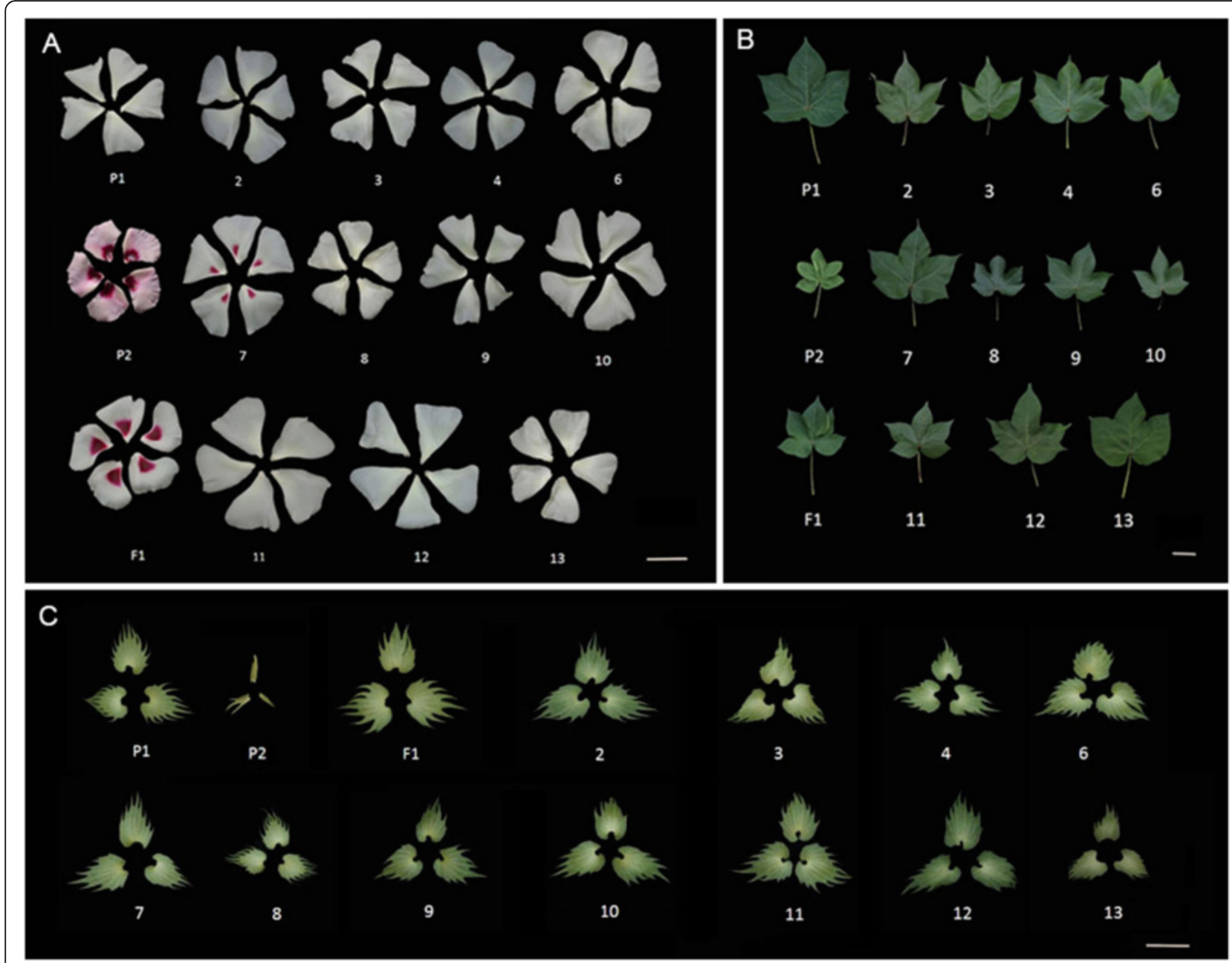

Fig. 5 Flower and leaf traits for MAALs of G. anomalum individual chromosomes in G. hirsutum. Flower-related traits were photoed on the flowering day (0 day post anthesis, 0 DPA). a (petal), b (top third leaf) and (c) (bract); P1, G. hirsutum. P2, G. anomalum. F1, the hexaploid of G. hirsutum and G. anomalum. 2-4 and 6-13 are plants that carried a single different individual chromosome from G. anomalum, corresponding to $2 \mathrm{~B}^{\mathrm{a}}, 3 \mathrm{~B}^{\mathrm{a}}, 4 \mathrm{~B}^{\mathrm{a}}, 6 \mathrm{~B}^{\mathrm{a}}, 7 \mathrm{~B}^{\mathrm{a}}$, $8 B^{a}, 9 B^{a}, 10 B^{a}, 11 B^{a}, 12 B^{a}$ and $13 B^{a}$. Scale bar $=50 \mathrm{~mm}$

University in 2014 spring at $25-28{ }^{\circ} \mathrm{C}$ and with $80 \%$ relative humidity. When they reached the fifth true leaf stage, the seedlings were transplanted into clay pots at PES/NJAU. Lastly, $38 \mathrm{BC}_{1}$ individuals were identified using SSR markers and GISH and consecutively backcrossed with TM-1. The $\mathrm{BC}_{2}$ seeds obtained were planted in the same way in spring 2015. In the winter, all plants were moved into the greenhouse at PES for preservation.

Scheme for developing the monosomic alien addition lines The interspecific hexaploid was backcrossed with Gossypium hirsutum acc TM-1 (obtained from the Southern Plains Agricultural Research Center, USDA-ARS) to produce the pentaploid $(2 n=5 \times=65$, AADDB genome), then the pentaploid progenies were further consecutively backcrossed with TM-1 to generate backcross progenies
$\left(\mathrm{BC}_{1}\right.$ and $\left.\mathrm{BC}_{2}\right)$. GISH was used to characterize alien chromosomes in all backcross progenies from the $\mathrm{BC}_{1}$ generation. When more than one alien chromosome was added from G. anomalum, the progenies were further backcrossed with TM-1 to produce monosomic alien addition lines. If only one alien chromosome was added to the background of Upland cotton, the progenies were further examined using chromosomespecific SSR markers of G. anomalum to determine the identity of the added chromosome.

G. anomalum, $\mathrm{TM}-1, \mathrm{BC}_{1}$, and $\mathrm{BC}_{2}$ chromosome preparation Cotton seeds were cultivated in an incubator at $29{ }^{\circ} \mathrm{C}$ and their root tips were cut off when they grew to $3 \mathrm{~cm}$ long (seedling plant). The tips were immersed in $25 \mu \mathrm{g} /$ $\mathrm{ml}$ cycloheximide at room temperature for $2 \mathrm{~h}$ to accumulate metaphase cells and then transferred to Carnoy I 

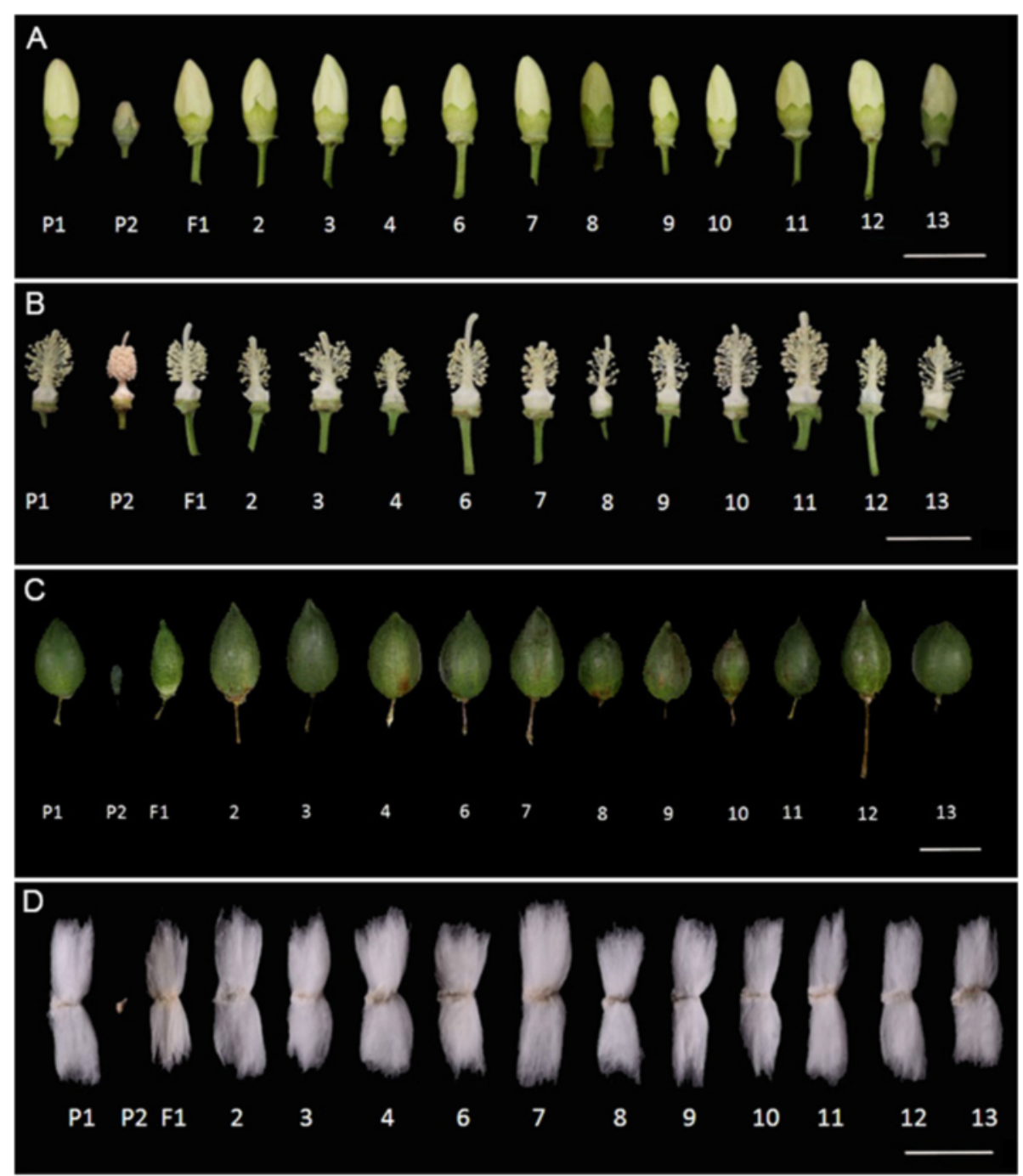

Fig. 6 Flower, boll and fiber traits of MAALs of G. anomalum individual chromosomes in G. hirsutum. Squares, pistils and bolls were photoed at -1 DPA, 0 DPA and 35 DPA, respectively. a (square), b (pistil), $\mathbf{c}$ (boll) and $\mathbf{d}$ (fiber); $P_{1}, G$. hirsutum. $P_{2}$, G. anomalum. $F_{1}$, the hexaploid of $G$. hirsutum and G. anomalum. 2-4 and 6-13 are plants that carried a single individual chromosome from G. anomalum, corresponding to $2 \mathrm{~B}^{\mathrm{a}}, 3 \mathrm{~B}^{\mathrm{a}}, 4 \mathrm{~B}^{\mathrm{a}}, 6 \mathrm{~B}^{\mathrm{a}}$, $7 B^{a}, 8 B^{a}, 9 B^{a}, 10 B^{a}, 11 B^{a}, 12 B^{a}$ and $13 B^{a}$. Scale bar $=50 \mathrm{~mm}$

Table 6 Fiber quality traits from some MAALs measured by HVI

\begin{tabular}{llllll}
\hline MAAL & Fiber length $(\mathrm{mm})$ & Fiber uniformity (\%) & Micornaire & Fiber strength (cN/tex) & Fiber elongation rate (\%) \\
\hline TM-1 & 29.08 & 86.20 & 4.35 & 31.95 & 7.00 \\
MAAL-2B & 27.99 & 83.80 & 4.66 & 29.60 & 6.70 \\
MAAL-4B & 26.02 & 83.60 & 4.52 & 28.32 & 6.50 \\
MAAL-6B & 25.84 & 82.20 & 5.43 & 30.67 & 6.80 \\
MAAL-8B & 26.99 & 83.40 & 4.04 & 32.44 & 6.60 \\
MAAL-10B & 25.94 & 83.10 & 3.35 & 35.67 & 6.70 \\
MAAL-13B & 27.17 & 84.70 & 4.78 & 28.91 & 6.50 \\
\hline
\end{tabular}


fixative containing 95\% ethanol and acetic acid (3:1, v/v) for at least $2 \mathrm{~h}$, digested in double enzymolysis liquid ( $4 \%$ cellulose: $1 \%$ pectinase $=1: 2$ ) at $37{ }^{\circ} \mathrm{C}$ for 45 min, and squashed in a drop of $45 \%$ acetic acid. Finally, slides containing at least 20 well-spread somatic chromosomes at mitotic metaphase were prepared and stored at $-70{ }^{\circ} \mathrm{C}$ overnight.

\section{Genomic in situ hybridization (GISH)}

Due to the very close relationships that exist between chromosomes of the B genome in G. anomalum and those of the At subgenome in G. hirsutum, two probes were employed here to avoid cross-hybridization between these chromosomes. Genomic DNA extracted from G. anomalum and G. herbaceum $(2 \mathrm{n}=2 \times=26$, AA genome) were labeled with digoxigenin-11-dUTP and Bio-16-dUTP (Roche Diagnostics, Mannheim, Germany) by nick translation, respectively. The probe fragment size was between 200-500 bp. Fluorescence in situ hybridization was carried out as described by [33] and [9] with some modifications. The mixing ratio of DNA probes from G. anomalum and G. herbaceum were adjusted to five different ratios, 2:1, 4:3, $1: 1,2: 3$, and $1: 2$, to determine the optimal ratio for discrimination of chromosomes from G. anomalum and the At-subgenome of G. hirsutum.

\section{DNA extraction and G. anomalum-specific primer screening}

Genomic DNA was extracted from young leaves of the two parents, G. anomalum and G. hirsutum acc. TM-1, the interspecific hexaploid, the pentaploid, and the $\mathrm{BC}_{1}$ and $\mathrm{BC}_{2}$ individuals using the method described by [34] with some modifications. A total of 2,168 pairs of SSR primers were selected from the high density genetic linkage map of Sea island and Upland cotton constructed in our institute [17] and employed to screen G. anomalumspecific primers. PCR reactions were performed and their amplified products were separated by PAGE, as described by $[35,36]$. The $G$. anomalum-specific marker primers obtained were further used to characterize each chromosome from G. anomalum.

\section{MAAL nomenclature}

Thirteen G. hirsutum-G. anomalum MAALs were named MAAL- $1 B^{\mathrm{a}}$ to MAAL- $13 \mathrm{~B}^{\mathrm{a}}$, according to the method described by [9], in which $B$ represents the $B$ genome of G. anomalum and 'a' refers to the initial letter of anomalum. The chromosome numbers 1 to 13 in the B genome of $G$. anomalum correspond to the homoeologous chromosomes in the Dt-subgenome of tetraploid cotton.

\section{Investigation of agronomic traits of monosomic alien addition line}

At the point of transition from the vegetative to the reproductive stage, the shape and size of fully expanded leaves from the same position in TM-1, G. anomalum, hexaploid and MAAL plants were investigated. Floral morphological traits from these MAALs were investigated in the flowering period. The size of cotton bolls at 35 days post-anthesis was also measured by vernier caliper. Finally, the hundred-seed weight, ginning outturn and single boll weight of the matured bolls were investigated. All the data were analyzed using the SPSS software version 18.0

\section{Additional file}

Additional file 1: Table S1. Incidence of alien chromosomes in the $\mathrm{BC}_{1}$ G. hirsutum $\times G$. anomalum generations. (DOC $33 \mathrm{~kb}$ )

\section{Abbreviations}

GISH: Genomic in situ hybridization; MAAL: Monosomic alien addition line; SSR: Simple sequence repeat

\section{Acknowledgements}

We acknowledge Dr Kunbo Wang, vice director of Cotton Research Institute of Chinese Academy of Agricultural Sciences, for providing seeds of Gossypium anomalum. We are also grateful to Dr RJ Kohel of the Southern Plains Agricultural Research Center, USDA-ARS, for providing seeds of Gossypium hirsutum acc TM-1.

\section{Funding}

The National Key Research and Development Program of China (2016YFD0100203), the National Key Technology R\&D Program of China during the Twelfth Five-year Plan Period [grant number 2013BAD01B03-04] and Jiangsu Collaborative Innovation Center for Modern Crop Production. The funders had no role in study design, data collection and analysis, decision to publish, or preparation of the manuscript.

Availability of data and materials

All data generated or analyzed during this study are included in this published article and its supplementary information files.

\section{Authors' contributions}

BLZ conceived and designed the experiments; XXW, YYW, CW, YC, YC, SLF and TZ performed the experiments; XXW, YYW and BLZ analyzed the data; $Y C, Y C$ and TZ contributed reagents/materials/analysis tools; BLZ and XXW wrote the manuscript. All authors confirmed their contribution, read and approved the final manuscript.

Competing interests

The authors declare that they have no competing interests.

Consent for publication

Not applicable.

Ethics approval and consent to participate

Not applicable.

\section{Author details}

${ }^{1}$ State Key Laboratory of Crop Genetics \& Germplasm Enhancement, Nanjing Agricultural University, Nanjing 210095, China. ${ }^{2}$ Key Laboratory of Cotton Breeding and Cultivation in Huang-Huai-Hai Plain, Ministry of Agriculture, Cotton Research Center of Shandong Academy of Agricultural Sciences, Jinan 250100, Shandong, People's Republic of China. 
Received: 12 June 2016 Accepted: 29 September 2016

Published online: 07 October 2016

\section{References}

1. Tang S, Teng Z, Zhai T, Fang X, Liu F, Liu D, Zhang J, Liu D, Wang S, Zhang K, Shao Q, Tan Z, Paterson AH, Zhang Z. Construction of genetic map and QTL analysis of fiber quality traits for Upland cotton (Gossypium hirsutum L.). Euphytica. 2015;201:195-213.

2. Fryxell PA. A revised taxonomic interpretation of Gossypium L.(Malvaceae). Rheedea. 1992;2:108-65.

3. Chen ZJ, Scheffler BE, Dennis E, Triplett BA, Zhang TZ, Guo WZ, Chen XY, Stelly DM, Rabinowicz PD, Town CD, Arioli T, Brubaker C, Cantrell RG, Lacape JM, Ulloa M, Chee P, Gingle AR, Haigler CH, Percy R, Saha S, Wilkins T, Wright RJ, Deynze AV, Zhu YX, Yu SX, Abdurakhmonov I, Katageri I, Kumar PA, Rahman M, Zafar Y, Yu JZ, Kohel RJ, Wendel JF, Paterson AH. Toward sequencing cotton (Gossypium) genomes. Plant Physiol. 2007;145:1303-10.

4. Qian SY, Huang JQ, Peng YJ, Zhou BL, Ying MC, Shen DZ, Hu TX, Xu YJ, Gu LM, Ni WC, Cheng S. Studies on the hybridof Gossypium hirsutum L. and G. anomalum and application inbreeding. Sci Agri Sin. 1992;25:44-51.

5. Ganesh SN, Vivek PC, Subhash SM, Ashok SJ. Interspecific hybridization in Gossypium L: characterization of progenies with different ploidy-confirmed multigenomic backgrounds. Plant Breed. 2013;132:211-6.

6. Mehetre SS. Wild Gossypium anomalum: a unique source of fibre fineness and strength. Curr Sci. 2010:99:58-71.

7. Narayanan SS, Singh J, Varma PK. Introgressive gene transfer in Gossypium. Goals, problems, strategies and achievements. Cot Fib Trop. 1984;39:123-35.

8. Stewart, JM. Potential for crop improvement with exotic germplasm and genetic engineering. In: Constable GA, Forrester NW, editors. Challenging the Future: Proceedings of the World Cotton Research Conference-1, Brisbane Australia, February 14-17, 1995. Melbourne; p. 313-327

9. Chen Y, Wang Y, Wang K, Zhu XF, Guo WZ, Zhou BL. Construction of a complete set of alien chromosome addition lines from Gossypium australe in Gossypium hirsutum: morphological, cytological, and genotypic characterization. Theor Appl Genet. 2014;127:1105-21.

10. Hau B. Ligne 'es d'addition sur Gossypium hirsutum L.I. Utilisation de I'hybridation interspe 'cifique et de lame 'thode des ligne 'es d'addition pour l'ame 'lioration ducotonnier. Cot Fib Trop. 1981;26:247-58.

11. Rooney WL, Stelly DM, Altman DW. Identification of four Gossypium sturtianum monosomic alien addition derivatives from a backcrossing program with G. hirsutum. Crop Sci. 1991;31:337-41.

12. Kynast RG, Riera-Lizarazu O, Vales Ml, Okagaki RJ, Maquieira S, Chen G, Ananiev EV, Odland WE, Russell CD, Stec AO, Livingston SM, Zaia HA, Rines HW, Phillips RL. A complete set of maize individual chromosome additions to the oat genome. Plant Physiol. 2001;125:1216-27.

13. Ahoton L, Lacape JM, Baudoin JP, Mergeai G. Introduction of Australian diploid cotton genetic variation into upland cotton. Crop Sci. 2003;43:1999-2005.

14. Sarr D, Lacape JM, Rodier-Goud M, Jacquemin JM, Benbouza H, Toussaint A, Palm R, Ahoton L, Baudoin JP, Mergeai G. Isolation of five new monosomic alien addition lines of Gossypium australe F. Muell in G. hirsutum L. by SSR and GISH analyses. Plant Breed. 2011:130:60-6.

15. Zhou ZH, Yu P, Liu GH, He JX, Chen JX, Zhang XX. Morphological and molecular characterization of two G. somalense monosomic alien addition lines (MAALs). Chin Sci Bull. 2004;49:910-4.

16. Gerstel DU, Sarvella PA. Additional observations on chromosomal translocations in cotton hybrids. Evolution. 1956;10:408-14.

17. Zhao L, Lv Y, Cai C, Tong X, Chen X, Zhang W, Du H, Guo X, Guo W. Toward allotetraploid cotton genome assembly: integration of a high-density molecular genetic linkage map with DNA sequence information. BMC Genomics. 2012;13:539. http://www.biomedcentral.com/1471-2164/13/539.

18. Friebe B, Qi LL, Nasuda S, Zhang P, Tuleen NA, Gill BS. Development of a complete set of Triticum aestivum-Aegilops speltoides chromosome addition lines. Theor Appl Genet. 2000;101:51-8.

19. Kishii M, Yamada T, Sasakuma T, Tsujimoto H. Production of wheat-Leymus racemosus chromosome addition lines. Theor Appl Genet. 2004;109:255-60.

20. Wang XE, Chen PD, Liu DJ, Zhang P, Zhou B, Friebe B, Gill BS. Molecular cytogenetic characterization of Roegneria ciliaris chromosome additions in common wheat. Theor Appl Genet. 2001;102:651-7.

21. Kong F, Wang H, Cao A, Qin B, Ji J, Wang S, Wang X. Characterization of T. aestivum-H. californicum chromosome addition lines DA2H and MA5H. J Genet Genomics. 2008;35:673-8.
22. Multani DS, Khush GS, delos Reyes BG, Brar DS. Alien genes introgression and development of monosomic alien addition lines from Oryza latifolia Desv. to rice, Oryza sativa L. Theor Appl Genet. 2003;107:395-405.

23. Chetelat RT, Rick CM, Cisneros P, Alpert KB, DeVerna JW. Identification, transmission, and cytological behavior of Solanum lycopersicoides Dun. monosomic alien addition lines in tomato (Lycopersicon esculentum Mill.). Genome. 1998:41:40-50.

24. Ali SNH, Ramanna MS, Jacobsen E, Visser RGF. Establishment of a complete series of a monosomic tomato chromosome addition lines in the cultivated potato using RFLP and GISH analyses. Theor Appl Genet. 2001;103:687-95.

25. Chen JF, Luo XD, Qian CT, Jahn MM, Staub JE, Zhuang FY, Lou QF, Ren G. Cucumis monosomic alien addition lines: morphological, cytological, and genotypic analyses. Theor Appl Genet. 2004;108:1343-8.

26. Chen CC, Chen SK, Liu MC, Kao YY. Mapping of DNA markers to arms and sub-arm regions of Nicotiana sy/vestris chromosomes using aberrant alien addition lines. Theor Appl Genet. 2002;105:8-15.

27. Reamon-Ramos SM, Wricke G. A full set of monosomic addition lines in Beta vulgaris from Beta webbiana: morphology and isozyme markers. Theor Appl Genet. 1992:84:411-8.

28. Gao D, Guo D, Jung C. Monosomic addition lines of Beta corolliflora Zoss in sugar beet: cytological and molecular-marker analysis. Theor Appl Genet. 2001;103:240-7.

29. Srinivasan K, Malathi VG, Kirti PB, Prakash S, Chopra VL. Generation and characterisation of monosomic chromosome addition lines of Brassica campestris - B. oxyrrhina. Theor Appl Genet. 1998;97:976-81.

30. Budahn H, Schrader O, Peterka H. Development of a complete set of disomic rape-radish chromosome-addition lines. Euphytica. 2008;162:117-28.

31. Zhou BL, Song C, Shen XL, Zhang XG, Zhang ZL. Construction of gene pools with superior fiber properties in Upland cotton through interspecific hybridization between Gossypium hirsutum and Gossypium wild species. Acta Agron Sin. 2003;29:514-9.

32. Shen X, Guo W, Zhu X, Yuan Y, Yu JZ, Kohel RJ, Zhang T. Molecular mapping of QTLs for fiber qualities in three diverse lines in Upland cotton using SSR markers. Mol Breed. 2005;15:169-81.

33. Wang K, Song XL, Han ZG, Guo WZ, Yu JZ, Sun J, Pan JJ, Kohel RJ, Zhang TZ. Complete assignment of the chromosomes of Gossypium hirsutum L by translocation and fluorescence in situ hybridization mapping. Theor Appl Genet. 2006;113:73-80

34. Paterson AH, Brubaker $\mathrm{CL}$, Wendel JF. A rapid method for extraction of cotton (Gossypium spp.) genomic DNA suitable for RFLP or PCR analysis. Plant Mol Biol Rep. 1993:11:122-7.

35. Zhang J, Guo W, Zhang T. Molecular linkage map of allotetraploid cotton (Gossypium hirsutumL. × Gossypium barbadense L.) with a haploid population. Theor Appl Genet. 2002;105:1166-74.

36. Zhang J, Stewart J. Economical and rapid method for extracting cotton genomic DNA. J Cotton Sci. 2000;4:193-201.

\section{Submit your next manuscript to BioMed Central and we will help you at every step:}

- We accept pre-submission inquiries

- Our selector tool helps you to find the most relevant journal

- We provide round the clock customer support

- Convenient online submission

- Thorough peer review

- Inclusion in PubMed and all major indexing services

- Maximum visibility for your research

Submit your manuscript at www.biomedcentral.com/submit
) Biomed Central 